\section{Perforator flaps}

\section{Dear Sir,}

I would like to draw attention to the term "Perforator based flaps". In the article "Distal perforator based cross leg flaps for leg and foot defects", published in the June 2005 issue. The photographs do not show the flap to be exclusively based on perforators, rather they can be called distally based fasciocutaneous flaps. Though I am aware that latter is a term based on composition and not vascular supply, all flaps in limbs except muscles are perforator based flaps as the supply is through arborisations of musculo or septocutaneous vessels. I would like to know if we can call non-islanded flaps as perforator based flaps or not.

\section{S. S. Chatterjee Department of Plastic Surgery, Institute of Post Graduate Medical Education \\ \& Research, Kolkata}

\section{Author's reply}

Dear Sir,

Thank you for giving us an opportunity to reply. We thank Dr SS Chatterjee for his interest in our work. The flaps that have been described in the article are perforator based flap as without the incorporation of distal perforators, flap of such noncoventional dimension will not survive. It is not necessary to show the perforators,as enough studies have been conducted to standardise these techniques.

Where the flap is islanded it is called skelitanized perforator based island flap. It is also a precise entity. Hope I have been able to answer adequately.

Thanking You,

\section{Bhattacharya}

\section{Anatomy of an internet consultation}

\section{Dear Sir,}

In today's fast moving medical advances the use of newer technology does present a real challenge to sort out true, genuine enquiries from deserving patients and from other categories, however expert you may be in handling it.

You will agree with me that when the enquiry comes by net we are really in a dilemma as to what to reply? Your reply can create unexpected problems from unexpected corners.

You will feel more safe \& comfortable to perform an 'Internet consultation' if you understand its anatomy.

Let us find out what precautions to take while on net by going into its details. There are unlimited problems to address about Internet usage but we will restrict to the above specific one.

Let us assume you have received an email asking about plastic surgery problem from person X. You have opened it and are happy to witness that you are becoming increasingly famous even on net and start thinking how to grace this occasion. And then you commit the mistake of replying it instantly in a big enthusiasm.

STOP!

Break this habit.

Instead of replying immediately try to dissect out the message to know the true motive.

Your aim should be only one i.e. you want to know whether mail sender is a genuine or hoax? And if genuine then how do I reply?

It is very easy.

There are certain traits of 'Email senders', which you must understand.

Please remember email is a way of communication between sender and receiver. Communication is a complex phenomenon that is usually ignored in routine clinical practice, yet getting it right has profound implications for the quality of patient care.

Sending and receiving messages are model-based processes. Consequently, the process of communication is fundamentally limited in its capacity not just by physical limitations of transmission channels, but also by the inherent limitations of modeling. What a message is meant to say when it is created, and what the receiver of a message understands, may not be the same.

Model theory tells us that the sender of a message is operating with models of the world that will always be inaccurate in one way or another, and that communication is done with the receiver who is supposed to be perfect in that field. So the receiver accepts and interprets the message in its true words. But in reality what is read \& perceived by the receiver is not necessarily being asked by the sender and vice versa. Consequently, communication will never be a perfect process, and misinterpretation is at 
some level unavoidable. It is the receiver's duty to understand the model of sender's environment in order to give better advice.

\section{Let us analyze the email step by step.}

All of you know that email contains following parts:

Subject, date, time, To, BCC, CC, Attachment, and main text.

\section{Now first concentrate on Subject}

A real patient who wants to consult only you (unlike a person who is taking many doctor's opinion) will write it as 'enquiry', 'can you help me', etc.

He will never write as 'help', 'doctor help me', 'Your charges', 'I seek your attention',' for your opinion', 'for your advice', etc. (I know these are very difficult to prove but are very much predictable once you get the whole picture of it). These subject lines indicates that the sender has probably mailed to many doctors at one go.

\section{Date/time}

If you are getting repeated emails from same person then 'time' category will help you very much. Because if the person is using cyber café then probably he will visit cyber at the same timings of the day and even might use the same computer every time. If he is using his office PC even then the timings will remain the same.

Ask him 'where does he work? If he doesn't reply then you know what it was? If he tells you about his working place then you should go back to the 'time of email sent': look whether timings are same or different.

If he is working in MNC, call center, foreign banks then all his emails will be stored in main PC of company which can be easily traced in case need arises.

Reluctance or refusal to provide accurate contact information such as a true phone number or address should spark red light in your mind.

\section{Name of the sender}

If the sender's name sounds funny then you will immediately come to know, so he will always use a real looking name followed by surname. But there will be a typical permutation combination of alphabets, which can be traced to his original name by the experts.

You will not believe but the 'psychological analysis' of the 'name used' will give lots of information about personality, family background \& other traits of the sender.

\section{Reply his mail asking for more information on his problems}

After your reply if there is no reply back or sender blocks your address then you know you have wasted few minutes of your energy unnecessarily.

Lets say he replies his details, now what? You do not want this soap opera to continue endlessly on your PC screen. Straight way tell him to see you in your clinic. Take my words if he really attends your clinic after this mail, he will become your true patient forever. Why? Because even he was assessing, comparing you with other doctors $\&$ has found you trustworthier.

\section{Now lets analyze other headers like To, BCC, CC}

Go to the 'tool bar' and click on 'view all headers' in your email. You will see the details of all other recipient's email ids and you will get some idea about the sender's intentions.

\section{Attachment}

Be careful in opening attachments from unknown sources. Unless you have strong 'antivirus' software do not take the risk of going in for it.

\section{Main Text}

This is the crux of the matter. You have to read in-between the lines. Watch out for these things

1. General language pattern: Whether it is polite, docile, convincing or rude, desperate, as if he is going to commit suicide if his request is not met with, do you think he is compelling you to give opinion about another surgeon's opinion. These warn you to be careful.

2. What is he asking?: Is he asking for advice, treatment, surgery, opinion or only wants to know the cost of surgery, where do you do the surgery? How many surgeries have you done? Can you give me their addresses? Answers to such questions are better avoided.

3. Spelling Mistakes: You will get lots of information from this feature of 'email analysis'. Few spelling mistakes here and there is a routine matter but hoax sender might commit many spelling mistakes even in a simple words because he wants to create an impression of a novice, he wants you to think that he is new to computers and is a 'gullible' target. 
He is inviting you in to his trap.

4. Way of putting things: If he comes straight to the point asking your advice then he may be genuine. But if he writes a long drama then he may not be genuine.

5. What are his demands?: See whether his demand are realistic or exaggerated ones.

6. His reply: Read his reply (if he sends one) how does it sound. Whether it is coherent with the first one or not.

7. Reference: He might even mention the name of a reference that gave him your name if he is genuine.

After performing this brain storming session. Think for a minute and then reply but carefully.

Of course Internet is a tool, which, everyone must use but just try to know safety issues.

For your benefit I would like to share some SAFTEY TIPS while 'emailing'

1. Never give your complete opinion to unknown persons on net.

2. Do not reply single doubtful email.

3. Never commit to meet person at any other place except your consulting / hospital premises

4. Never quote your charges on net. (However big or small it may be.)

5. Never comment on other doctor's results by looking at a patients' photograph.

6. If you have pc-imaging facility then never give a print out or jpeg image to patient.

9. Just tell the email sender to see you in your clinic.

10. Your email program should have a way for you to disable the automatic running of macros and other programs that you receive via email.

11. Never give your credit card number or family details on net.

12. Do maintain cordial relations with all your colleagues and in case of any doubtful email or dubious patients do tell them about it and take their opinion.

A. Nirale

Aakar Plastic and Cosmetic Surgery Center, A/6 'Vyomesh' S.V.Patel Rd. Borivli West, Mumbai-400092, India. E-mail: drnirale@yahoo.com 